\title{
Reflexiones y refracciones modernas: el advenimiento de la enseñanza del Diseño en la Universidad Nacional de Seúl entre las décadas de 1940 y 1970*
}

\section{Resumen}

El presente artículo reporta una investigación que tiene como objetivo analizar el modo en que devino la enseñanza del diseño en la Universidad Nacional de Seúl (SNU) entre las décadas de 1940 y 1970. Para ello se optó por seguir una metodología cualitativa de análisis de contenido, ya que debido a los escasos estudios precedentes y a falta de un organismo que cuente con un registro de materiales de archivo organizado, el estudio tuvo que iniciar con las tareas de recopilación, ordenamiento, interconexión e interpretación de diferentes documentaciones.

La elección de la alfabetización del diseño de la SNU como objeto de estudio se centró en la importancia que tiene la universidad como institución nacional, pues esta fue pionera en incorporar la enseñanza del diseño, e influyó posteriormente con su proyección pedagógica en la corriente de pensamiento y acción de las diferentes universidades, empresas y proyectos gubernamentales.

Respecto a los resultados de la investigación, se pudieron observar dos cuestiones. Primero, la formación en la educación del Diseño en la SNU estuvo íntimamente relacionada a un contexto histórico que negaba la existencia de un concepto cultural estético por fuera del Diseño Occidental. En los inicios del departamento de Artes Aplicadas, este hecho reflejó la tensión entre las corrientes de educación japonesa y norteamericana. Segundo, se privilegió la incorporación de docentes capacitados en EE. UU. en un afán por superar la impronta del colonialismo japonés. Esta aplicación indiscriminada de contenidos occidentales desencadenó una confusión general en los inicios de la carrera que, sin superar la pedagogía previa, se reflejó en la comprensión del diseño — por la SNU y más tarde por parte del Gobierno- como un mero arte decorativocomercial. Este hecho se reflejó en que el diseño se diera a conocer en Corea como una actividad decorativa rentable, destinada a la producción de objetos coreanos diseñados bajo una forma universal exportable.

\footnotetext{
* Agradecimientos: Esta investigación contó con el apoyo de las diferentes instituciones mencionadas en el artículo. No obstante, más allá del respaldo institucional, quisiera agradecer a todos los que, con sus saberes y su generosidad, su calidez y su tiempo, me alentaron a llevarlo a cabo. En primer lugar, a los profesores Sergio Rybak y Walter Castañeda quienes siempre estuvieron presentes con sus atentas lecturas y generosos comentarios. A mis amigos Óscar Villota y Mercedes Fernández Cantón con quienes compartí revisiones, dudas y desalientos. Finalmente, agradezco a los evaluadores de la revista Kepes por sus meticulosas revisiones y el apoyo simbólico del profesor Kim Min Soo por todas sus enseñanzas en la SNU.
}

\section{Eliana Kim}

Doctora de Historia y Estudios Culturales de Diseño.

Docente e Investigadora, Universidad Nacional de Seúl, Corea del Sur.

Correo electrónico:

kimeliana@ymail.com

(ㄱ) orcid.org/0000-0002-4470-3272

Google Scholar

Recibido: enero 28 de 202 Aprobado: julio 15 de 2021

\section{Palabras clave:}

diseño, colonialismo, Corea del Sur, educación del diseño, modernidad. 


\section{Modern Reflections and Refractions: The Advent of Design Education at Seoul National University between the 1940s and the 1970s}

\begin{abstract}
This article reports research that aims to analyze the way in which the teaching of Design in the Seoul National University (SNU) came about between the 1940s and the 1970s. For this purpose, it was decided to follow a qualitative methodology of content analysis since, because of the few previous studies and the lack of a body that has an organized record of archival materials, the study had to begin with the task of compiling, ordering, interconnecting, and interpreting different documents.

The choice of the literacy design at SNU as an object of study focused on the importance the University has as a national institution since it was pioneer in incorporating the teaching of design, and subsequently it influenced the current of thought with its pedagogical projection and action of the different universities, companies, and government projects.
\end{abstract}

Regarding the research results, two situations became evident. First, training on Design education at SNU was closely related to a historical context that denied the existence of an aesthetic cultural concept outside of Western Design. In the early days of the Department of Applied Arts, this fact reflected the tension between the Japanese and North American educational trends. Second, the incorporation of teachers trained in the United States was favored in an effort to overcome the imprint of Japanese colonialism. This indiscriminate application of Western content unleashed a general confusion at the beginning of the major that, without going beyond the previous pedagogy, was reflected in the understanding of design - by the SNU and later by the government- as a mere decorative commercial art. This fact was reflected in the fact that design became known in Korea as a profitable decorative activity aimed at the production of Korean objects designed in a universal exportable form.
Key words:

design, colonialism, South Korea, design education, modernity. 


\section{Introducción}

El presente artículo analiza el modo en que han devenido el desarrollo, la concepción académica del diseño y la alfabetización de las formas del diseño en la Universidad Nacional de Seúl (SNU) entre las décadas de 1940 y 1970, para entender dos cuestiones: el establecimiento de los estilos y técnicas occidentales y el fenómeno de la resignificación social del diseño en Corea del Sur.

Hoy en día, la carrera de Diseño como disciplina global tiene por objetivo la enseñanza creativa y técnica para idear un artefacto, servicio o interfaz que pueda producirse en serie por los diferentes medios industriales. Esta carrera se dedica a la creación de sistemas aplicables a la enseñanza del diseño y da lugar al planeamiento, la estrategia, la gestión y la metodología de diseño de productos y servicios. De esta manera, se otorga tanta importancia a los aspectos técnicos e industriales como a los saberes estéticos y proyectuales.

No obstante, es imposible afirmar que dicho estándar universal haya surgido deliberadamente a través de un acuerdo democrático de orden mundial. La educación del diseño, asentada con la Bauhaus en Alemania (1919), los Vkhutemas en Rusia (1920) — los dos en forma casi simultánea_y la Escuela de Cranbrook (1932) en EE. UU., logró su expansión global luego de la Segunda Guerra Mundial. Fue en dicho momento que diferentes asociaciones de diseñadores de Japón, EE. UU., Gran Bretaña y Alemania, entre otros, decidieron definir el diseño al conferirle un carácter científicouniversal (Campi, 2015, pp. 7980). En este punto, es importante mencionar que existen otros estudios que se concentran en el análisis de la estética y la funcionalidad de los diseños de la vida cotidiana como son las investigaciones de Mumford (1934), Giedion (1948), Schaefer (1970) y Forty (1986). Sus estudios dejan en evidencia que la funcionalidad y los avances tecnológicos han contribuido a 
la evolución del Diseño Moderno (Mumford, 1934; Giedion, 1948) y que los artefactos diseñados guardan una íntima relación en la manera de consumo y la sociedad en la que se desarrolla (Forty, 1986). Todos ellos logran extender el panorama de la mirada canónica que destaca la creatividad individual de los Pioneros del Diseño Moderno (Pevsner, 1949). En especial, la obra de Herwin Schaefer (1970) remarca que es necesario superar dicha mirada distorsionada del diseño y que el estilo funcional — tradicionalmente asociada con el Diseño Moderno del siglo XX- existió en el diseño vernacular de los objetos cotidianos. Este hallazgo podría demostrar que el diseño racionalfuncionalista ha sido una elección evolutiva de la sociedad europea sin fines academizantes. Sin embargo, es necesario remarcar la diferencia entre un proceso electivo y condicionado. Dicha adaptación intuitiva hacia la forma funcional sin excesos decorativos que aparecieron en los siglos anteriores en Inglaterra, dista de los parámetros académicos-institucionales del Buen Diseño Industrial que debieron acatar las sociedades sin desarrollo industrial como es el caso de Corea.

La definición, la sistematización y la difusión de las actividades del diseñador industrial comenzaron por iniciativa del Consejo de Diseño Industrial (Council of Industrial Design - COID_- como parte de un proyecto elitista globalizante (Pulos, 1989, pp. 216217). De este modo, se puede inferir que gran parte de la causalidad de la universalización de formas se ha conseguido a través de un acuerdo entre diferentes países desarrollados, y esta definición se expandió a otras regiones a través de la enseñanza superior.

Como una de las sociedades que más han invertido en educación durante el período de industrialización y desarrollo (19601990), Corea del Sur creía que la educación superior sería el instrumento que lograría el anhelado progreso. Lo demostró cuando cumplió su milagro económico (Cauzzi de Gosende, 1996). La enseñanza del diseño también se fomentó en función de la misma 
causa, pues el diseño funcionó como herramienta para el desarrollo del país a través de la producción de nuevos productos y cánones exportables desde los años 70 (Korea Design Packaging Center, 1990).

La educación del diseño en la SNU como universidad estatal estuvo íntimamente ligada a los fines del Gobierno. Fue una de las primeras universidades que incorporaron la enseñanza del diseño en su programa curricular. Asimismo, los docentes y los exalumnos, a través de sus funciones por fuera de la universidad, fueron responsables de que su contenido se expandiera — mediante objetos, sujetos y acciones - en diferentes entidades públicas y privadas. Es decir, revisar la formación de la educación del diseño en la SNU es crucial para comprender luego el desarrollo de la praxis de la disciplina.

Sin embargo, y a pesar de su importancia, la cantidad de investigaciones históricas críticas sobre la educación del diseño sigue siendo escasa. Entre las fuentes secundarias más relevantes se pueden mencionar: el estudio de MinSoo Kim, uno de los primeros en reordenar la historia de la carrera de Diseño en la SNU de 1946 a 1996 y quien remarcó la influencia educativa japonesa en los inicios de la carrera de Diseño (Kim, 1996); las series bibliográficas de Historia de la Escuela de Bellas Artes de la SNU (Universidad Nacional de Seúl, 1993); la colección de libros de entrevistas a profesores del Departamento de Diseño (Kim, 2013a, 2013b; Park, 2013a, 2013b) editadas por la misma universidad, y otras investigaciones destinadas a personajes específicos (Her, 2009; Jeong, 2010) o que poseen algún capítulo con datos académicos (Jongkyun, 2015).

Además, es importante aclarar que las críticas sobre la historia del diseño comenzaban recién a fines de 1999 a través de la revista The Journal of Design Culture and Criticism. Estas críticas del diseño marcaron el punto de partida para corregir gran parte de las problemáticas de producción, formales y estéticas del diseño nacional, que se habían venido naturalizando hasta el 
año 2000. Además de ello, la teoría e historia del diseño se profundizaba en 2013 con la apertura del Departamento de Posgrado de Historia y Cultura del Diseño de la SNU. Allí se desarrolló por primera vez la labor de retrospección, ordenamiento y descripción de materiales de archivo inéditos, al igual que la investigación de la historia del diseño coreano por fuera de la filosofía occidental. Este trabajo surge como resultado parcial de dichos estudios.

\section{Metodología}

La investigación a la que hace referencia este artículo inicia con las preguntas: ¿cómo deviene la concepción académica del diseño y su alfabetización de la primera universidad nacional?, ¿quiénes son los actores y cuáles son los factores que inciden en el proceso de formación de la carrera del Diseño?, ¿qué intereses políticos confluyen en la conformación de la educación de Diseño?, ¿cuáles fueron los resultados académicos y cómo influyen en la sociedad? Para contestar a dichas cuestiones, la investigación optó por seguir una metodología cualitativa de análisis de contenido, pues debido a la escasez de estudios precedentes y la falta de un organismo que cuente con un registro de materiales de archivo organizado, el estudio dio inicio con las tareas de recopilación, ordenamiento, interconexión e interpretación de diferentes documentaciones.

Primero, se ha implementado una rigurosa recolección e interpretación de diversas fuentes primarias de carácter impreso e icónico. La labor consistió en el recaudo de fuentes primarias tales como: artículos periodísticos y de revistas de la época como Korea Design Packaging Center, Gegan Design y MiDae HakBo; fotografías, libros y escritos pertenecientes a los profesores del primer Departamento de Diseño, y los catálogos de exposición de los alumnos conservados por el Instituto de Artes Visuales de la SNU; las fotografías de los primeros talleres, los esquemas concedidos por el museo de la SNU 
y programas de clases otorgados por el archivo de la oficina central de la misma universidad. Adicionalmente, se recopilaron contratos oficiales y otras documentaciones nacionales oficiales del Instituto Nacional de Historia de Corea y el Archivo Nacional de Corea del Sur. Asimismo, se ha trabajado con las fuentes secundarias mencionadas en la Introducción del artículo ${ }^{1}$ para ubicar dichos análisis de los materiales académicos en la historia del diseño de Corea.

Luego de la recolección y categorización de los documentos se ha procedido a un doble análisis de tipo externo e interno para obtener una lectura profunda de cada una de las documentaciones y su relación con la compleja trama sociohistórico nacional. En tanto que el análisis interno se realiza con relación al sentido y las características individuales de cada documento, el análisis externo procura ubicar los documentos en un contexto social, político y económico (Noguero, 2002, p. 172). De este modo, esta técnica permite analizar el mensaje manifiesto en el contenido latente de las documentaciones en el contexto social en donde se desarrolló (Abela, 2002).

El estudio se divide en tres partes: la primera trata del contexto sociohistórico de colonialismo japonés y el período de reconstrucción bajo el gobierno militar americano, ambos antecedentes necesarios para la constitución del concepto de diseño en Corea del Sur.

La segunda retoma el proceso de formación del Departamento de Diseño en la SNU mediante el análisis y la interpretación de los proyectos de graduación de los primeros alumnos, y establece la interconexión entre los programas de las clases y el material de archivo donado por la primera cohorte de profesores. En esta parte, se hace hincapié en la lucha de poderes de corrientes japonesas y norteamericanas que existió en los inicios de la carrera. 
La tercera analiza los resultados proyectuales de la nueva generación de profesores formados en el exterior a través de las becas concedidas por la International Cooperation Administration (ICA) y el proceso de asimilación de los alumnos en sus resultados proyectuales. Se interpreta dicho período como el momento de inflexión en el cual se consolida la educación canónica del diseño y su actividad se difunde a través de la participación de los profesores y alumnos en los proyectos nacionales subvencionados por el gobierno de Park.

La investigación tiene como objeto de estudio la educación del diseño de las primeras décadas de la SNU, ya que se intuye que la comprensión del modo en el que devino la primera educación formal de esta disciplina en Corea constituye uno de los pilares fundamentales del proceso de naturalización (Barthes, 1972) y asimilación de formas de diseño occidentales. Su importancia está en el proceso de desnaturalizar el concepto de diseño como algo democrático y universal y, en cambio, considerarlo un saber instrumental y formal, reflejado en la enseñanza y profesionalización que, como resultado, se evidencia en diversos productos destinados al mercado interno y externo.

\section{Discusiones}

\section{El diseño traducido como "dibujo de mesa" y el intento de un diseño industrial sin industria}

Para comprender el advenimiento de la educación del diseño en la SNU, es preciso abordar brevemente el contexto sociopolítico, la manera en que ingresa el concepto del diseño a Corea y sus períodos históricos de occidentalización. El Diseño Occidental no puede negar la modernidad²

\footnotetext{
${ }^{2}$ Como bien había descrito Marshall Berman (2011), la modernidad es un período histórico filosófico en el cual se da lugar a una vorágine de experiencias sociales, políticas y económicas que desarman una tradición sólida con paradigmas dominantes y constituye una nueva concepción del mundo. Siguiendo este concepto, en este artículo se menciona la modernidad como un proceso complejo de cambios y rupturas en distintos ámbitos de la vida occidental — como la religión, la ciencia, el arte, la política, la filosofía, entre otros_ durante los que tiene lugar el desarrollo
} 
ni la occidentalización; tampoco puede negar su cara colonial. Como bien remarca el sociólogo argentino Mignolo (2011), la colonialidad de Occidente está presente como su lado oscuro, y esta característica se manifiesta también en la intromisión formal del diseño. En el caso de Corea, esta cuestión se desarrolla en dos instancias. La primera se desprende del ingreso del término Design en un trasfondo de modernización interrumpida por el colonialismo japonés (19101945). La segunda tiene que ver con el período de dominación cultural norteamericana, en el que se inculca la importancia comercial del producto por encima de los fundamentos sociales.

El colonialismo japonés en Corea se considera como una época de occidentalización mediada, donde rigió la imposición de valores estéticos japoneses por sobre los nacionales. Por ejemplo, la cerámica nacional, descalificada en 1924 como objeto que denotaba la "belleza de la tristeza" por el crítico de arte japonés Yanagi Muneyoshi (Choi, 2009), fue una de las tantas valoraciones negativas que le fueron concedidas al arte tradicional por parte de Japón. En este contexto, el Diseño Occidental ingresaba traducido como DoAn — "Dibujo de Mesa" —, que implicaba la reducción del término a las características meramente formales y estéticas decorativas que recubrían las superficies de los productos. Al mismo tiempo, a falta de escuelas de enseñanza superior de artes y técnicas en Joseon, desde 1880 surgió una gran cantidad de estudiantes que decidieron irse a estudiar al extranjero. Entre los destinos más elegidos se encontraban EE. UU. y Japón, pero la segunda elección fue gradualmente ascendiendo durante el período colonial (Lee, 2017, p. 233).

Luego de la liberación de la tutela japonesa en 1945, en una Corea con un estado de economía agraria muy pobre y con vestigios de guerra, se fundaron

del sistema capitalista a través de la Revolución Industrial y surgen los nuevos estados-naciones a través de la Revolución Francesa. Dicho proceso de reorganización y redefinición política, económica y social occidental, se extiende a diferentes partes del mundo a través de la colonialidad. En el caso de Joseon (actual Corea del Norte y Corea del Sur), la modernidad se desarrolla durante el período de colonialismo japonés (1910-1945) y es por ello que se le denomina Modernidad Colonial. 
la Escuela de Bellas Artes de la SNU y el primer centro de diseño Handicraft Demonstration Center (HDC) bajo el orden militar de EE. UU. El HDC, establecido en mayo de 1958, comenzó a funcionar bajo la coordinación de la empresa Smith, Sherr \& McDermott (SSM) asignada por la ICA como parte del proyecto de asistencia económica del Plan Marshall. Entre los objetivos del centro se encontraban la enseñanza y la promoción del diseño industrial. Es por ello que la ICA comenzó a promocionar la educación en la SNU y la Universidad Hongik. Como resultado, veintisiete de los estudiantes graduados más distinguidos fueron elegidos como pasantes en el HDC (Command, 1958). Entre ellos estaba Min Cheol Hong, Sun Hyeon Kwon y otros dos graduados de la SNU becados por el director del centro, Norman R. De Haan, para que fuesen por un año a aprender diseño a EE. UU.

En cuanto a la educación desarrollada en el centro, las actividades remarcaban la importancia comercial del diseño. En 1958, en un país sin desarrollo industrial, los diseñadoresinstructores enseñaban a analizar los productos más vendidos en el extranjero, atraídos por la empresa SSM. Su objetivo estaba en capacitar a sus alumnos para rediseñar productos tradicionales coreanos de manera artesanal, pero orientados a imitar el lenguaje formal de los ejemplos que habían expuesto. Estos productos ganaban premios de Buen Diseño en los stands americanos y se vendían satisfactoriamente. De este modo, era evidente que el mecanismo de refuerzo positivo implementado por el HDC dejaba entrever las posibilidades de la enseñanza y práctica de los "dibujos de mesa", que más allá de ser motivos estéticos decorativos, podían llegar a ser herramientas rentables para el gobierno desarrollista de Jung Hee Park (1961-1979). 


\section{La formación de la enseñanza del diseño en la SNU}

En este contexto histórico sinuoso de colonialidad (Kim, 2020, p. 29), en el cual las nuevas maneras de encarar el diseño se perfilaban a través de las incongruentes vertientes imperialistas, se fundaban las bases de la enseñanza del diseño en Corea del Sur. La SNU se estableció en 1946, a un año de la "independencia" del colonialismo japonés y a comienzos de su dependencia económicocultural del gobierno americano. En la misma fecha, la Escuela de Bellas Artes iniciaba sus actividades y, si bien la primera asignatura con el nombre Design aparecía en 1976, la manera de incorporar su contenido y su enseñanza estaba desde sus inicios.

La educación de la Escuela de Bellas Artes de la SNU (Figura 1) como entidad educativa establecida durante el gobierno militar del ejército de EE. UU. (1945-1948) no podía negar su influencia norteamericana. Sin embargo, la impronta de la educación japonesa del diseño siguió muy presente a través de la primera camada del staff docente, que había ingresado a la universidad luego de haber terminado sus estudios en la Escuela de Bellas Artes de Tokio, Japón. Desde sus inicios hasta mediados de los años 70, como mencionó BooHyun Her (2009), la singularidad de la Escuela de Bellas Artes estaba en seguir el sistema educativo integrado norteamericano, combinado con la educación japonesa del departamento de DoAn (p. 61). Entre estos dos grupos se encontraban: los profesores que habían vuelto de realizar sus estudios de DoAn en Japón — como el caso de Sun Seok Lee_- y el director de la Escuela de Bellas Artes, Louis Pal Chang, que había entendido la importancia de la enseñanza del diseño durante su estancia en EE. UU. Ambos perfilaron una orientación diferente de la carrera basándose en sus conocimientos adquiridos en el extranjero. 
Sun Seok Lee comenzó su enseñanza como profesor titular del Departamento de DoAn (Figura 2). En sus inicios, con la incorporación de DoAn, la transferencia de la enseñanza del diseño en la Escuela de Bellas Artes de Tokio se había manifestado sin ningún cambio en la SNU. De hecho, al inicio de la carrera, el programa de clase se había planeado con base en la educación recibida por Lee y los otros profesores que fueron incorporándose más tarde. Pero, a pesar de que el nombre del Departamento cambió por Artes Aplicadas en 1950, como una manera de dejar la impronta del país que había colonizado a Corea (Instituto de Artes Visuales, 2016, p. 25), tanto el programa curricular como la metodología de enseñanza se mantuvieron por la siguiente década sin modificaciones evidentes hasta mediados de los años 70, cuando finalizó la labor académica de Lee.

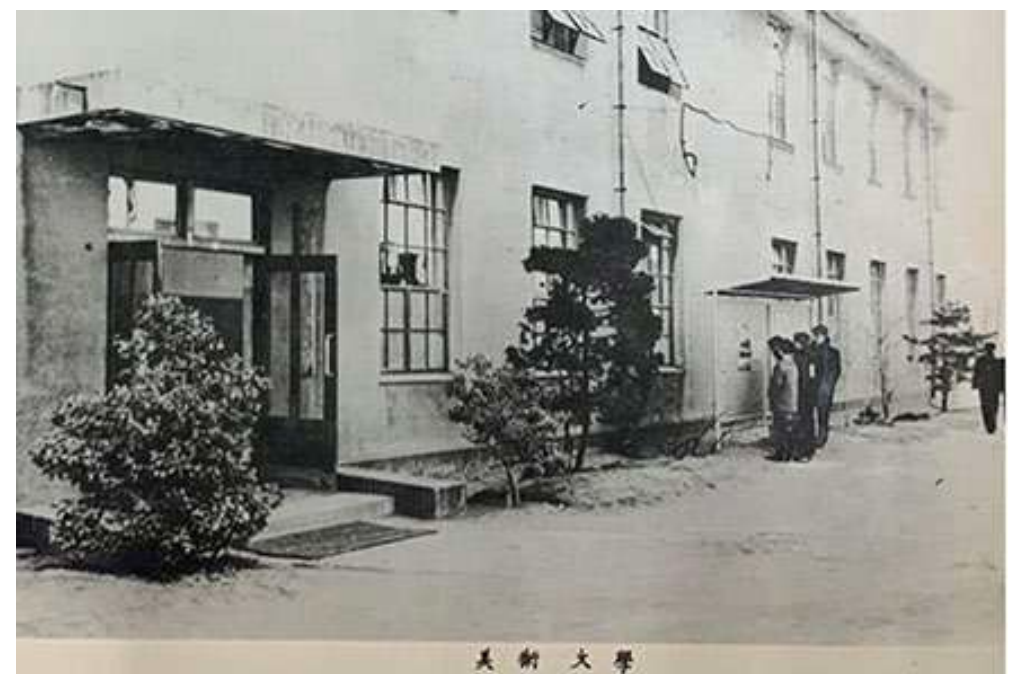

Figura 1. Fachada del primer Departamento de Bellas Artes de la Universidad Nacional de Seúl. Fuente: SNU, Museo de Arte. 


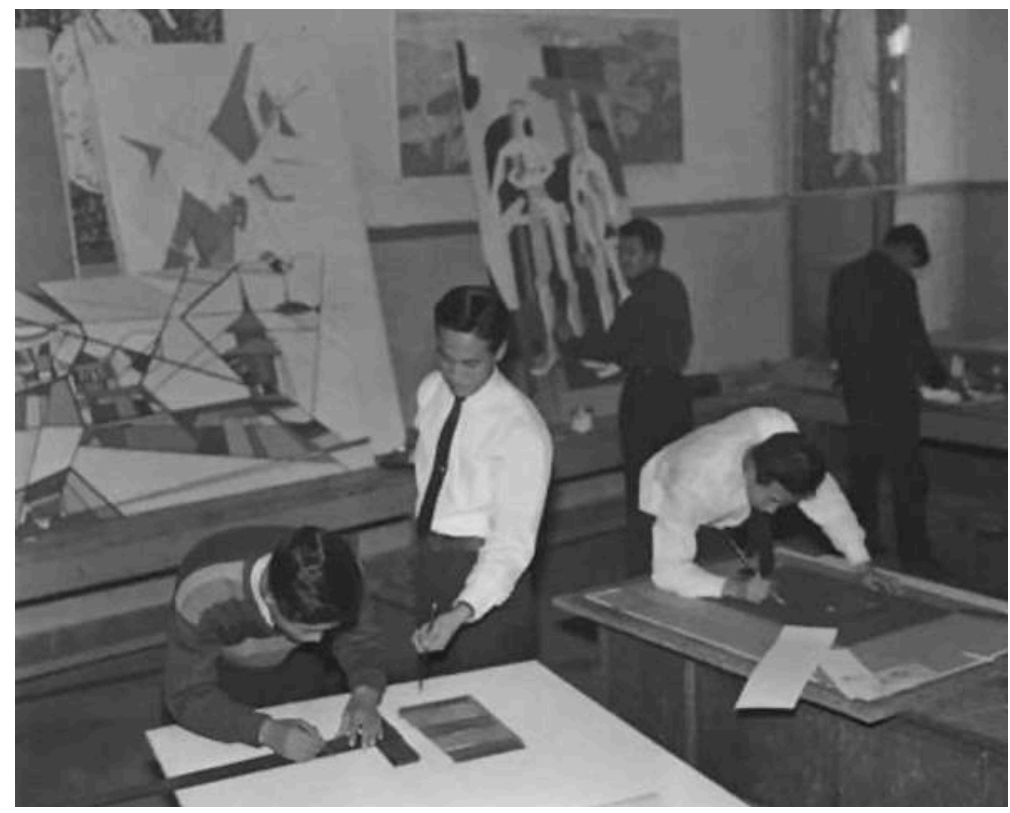

Figura 2. Alumnos trabajando en el departamento de Do-An de la Universidad Nacional de Seúl en 1954. Fuente: SNU, Museo de Arte.

El programa académico del Departamento de Artes Aplicadas se dividía en cuatro años lectivos. El primer año estaba destinado a un ciclo básico y desde el segundo año las materias se dividían en obligatorias y electivas. Dentro de la primera categoría se encontraban las materias Arte Artesanal y Arte Industrial, que se impartían desde el segundo año; en el tercer año se incorporaba Arte Escénico, y en cuarto año Arte Publicitario (Her, 2009, p. 69). Lee se encargó de gran parte de las asignaturas que en ese momento sustituían el Diseño Industrial, impartidas bajo los nombres de Arte Artesanal y Arte Industrial; Arte Comercial, por su parte, 
equivalía al Diseño Gráfico. La forma de enseñanza se basaba en la reproducción de figuras, estilos lineales y planos propios del estilo pictórico japonés.

Como ilustran los casos de las figuras 3 y 4, los estudiantes presentaban sus proyectos de graduación como dibujos en perspectiva, planta frontal y lateral, bajo el título de DoAn. Ninguno tenía en cuenta la materialidad, la técnica de producción o la mecánica de funcionamiento o uso. Por esto, si bien las consignas de los trabajos prácticos estaban emparentadas a las bajadas de diseño actual — como es el ejemplo de diseño de calendarios, carteles, muebles, packaging-, los alumnos nunca lograron pasar del esquema conceptual a la producción real. Estas características dificultaban la comprensión de otros estudiantes que, al ver dichos paneles, se preguntaban si el contenido de estos era o no diseño.

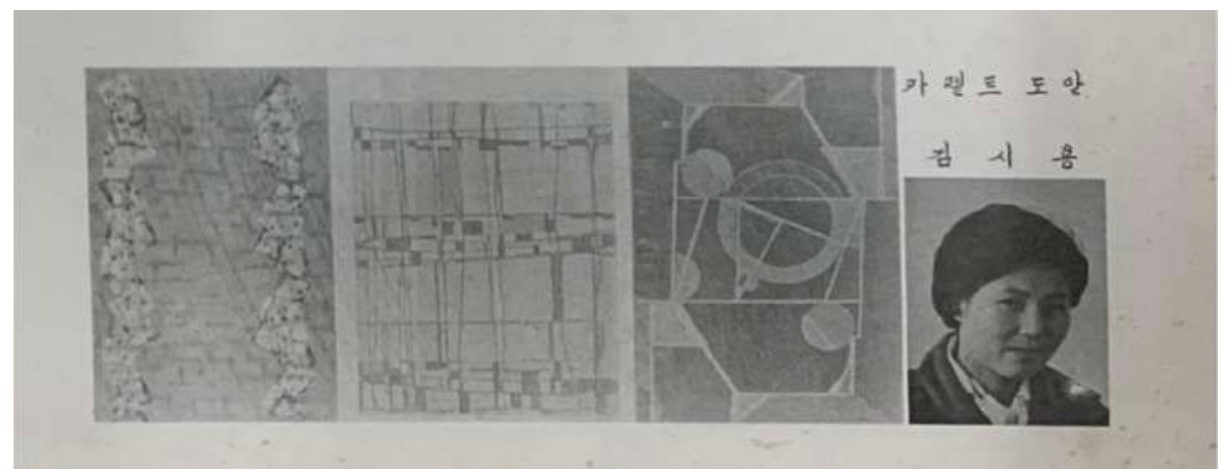

Figura 3. Egreso de la primera camada de estudiantes de Artes Aplicadas. El proyecto final de Si Yong Sim. Diseño (DoAn) de alfombras. Fuente: SNU, Visual Art Institute. 


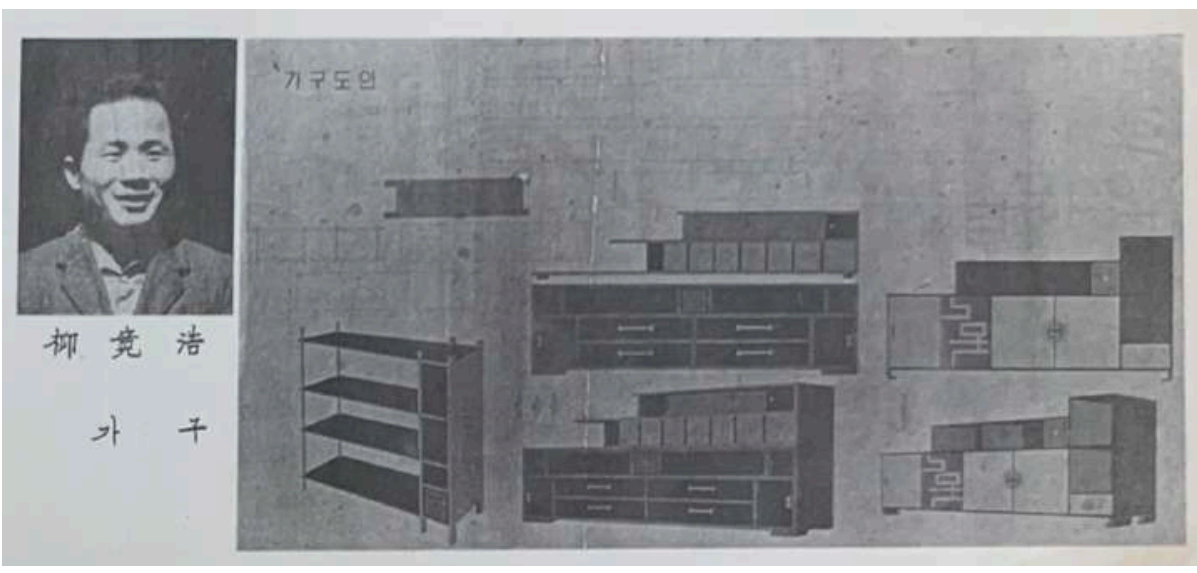

Figura 4. Egreso de la primera camada de estudiantes de Artes Aplicadas. Proyecto final de Kyuan Ho Yoo. Diseño de mueble. Fuente: SNU, Visual Art Institute.

Paralelamente, Louis Pal Chang como director de la Escuela de Bellas Artes representa la contracara de la enseñanza japonesa. Su interés por inclinar el transcurso de la educación del diseño hacia el modelo americano se manifestó en varias oportunidades. Su atención estaba puesta en la pauta teóricocientífica que impulsó el armado curricular, así como también en la petición que le hacía al staff docente de estructurar sus clases de manera más sistemática. Chang introdujo el ciclo básico fundacional desde los comienzos de la Escuela de Bellas Artes, para la cual creó las asignaturas de Fotografía, Caligrafía Coreana, Estructura, Ética y Moral, Composición y Escultura —que él mismo dirigió-. Además, para la cursada de grado incorporó las materias teóricas Historia del Arte Asiático, Historia del Arte Occidental, Teoría del Arte, Estética y Contemplación Artística, y así lograr un balance entre las teóricas y las prácticas (Jeong, 2010, p. 31). Además, tuvo la oportunidad de formar parte del proyecto de intercambio con la Universidad de Minnesota, por el cual fue aceptado como profesor invitado durante la Guerra de Corea (19511953). 
De esta manera, Chang tomó toda clase de iniciativas para cambiar el modelo educativo, en el que aún prevalecían las clases dictadas por la camada de profesores que habían terminado sus estudios en Japón. No obstante, su esfuerzo por querer eliminar todo vestigio del "dibujo de mesa" y su devoción hacia el modelo educativo norteamericano terminó resultando cuestionable por varias razones. La primera tenía que ver con la elección del contenido de las asignaturas. Entre las que había a su cargo, se encontraban Historia del Arte Occidental y Composición, basadas en los conocimientos que había adquirido durante su viaje de estudios. Historia del Arte Occidental tenía como bibliografía principal el libro Art through the ages de Helen Gardner (Park, 2013a, p. 52). En cuanto a Composición, el nombre y su contenido hacían honor a la clase de Arthur Wesley Dow que él había recibido en la Universidad de Columbia (Kim, 1996, p. 36). Sin embargo, la aplicación de los temas aprendidos en Norteamérica no significaba que el contenido fuese un legado occidental, ni que estuviese libre de influencias del estilo japonés. En particular, si las clases de Composición estaban basadas en las de Arthur Wesley Dow, debía tenerse en cuenta la gran cantidad de material de su libro Composition (Figura 5) estaba dedicado al DoAn (Dow, 1913). El interés de Dow por la cultura japonesa se dio por influencia de su encuentro en 1880 con el japonólogo Ernst Fenellosa en el Museo de Boston. El mismo Dow afirmó haber aplicado en 1889 las técnicas aprendidas en sus clases de arte de Boston (Dow, 1920, pp. 1517). De este modo, se puede deducir que la propia clase de Chang no había marchado conforme a su propósito. 


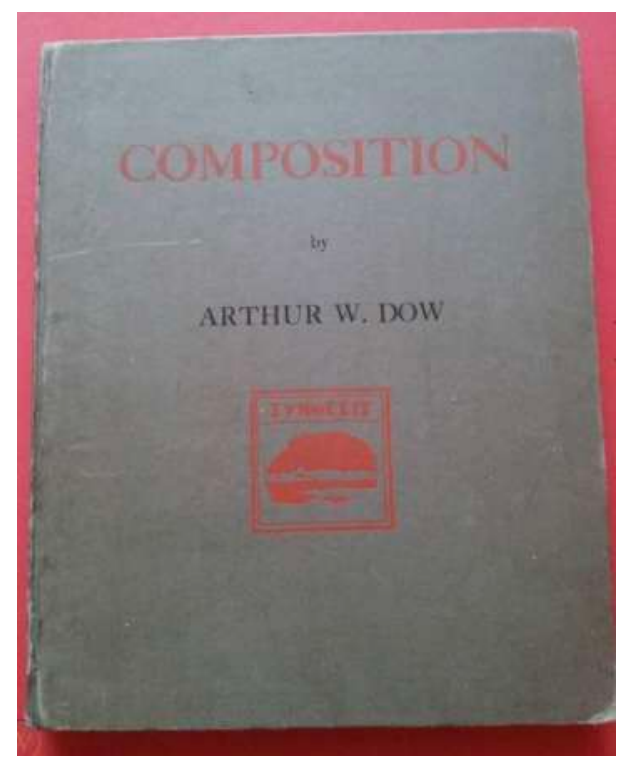

Figura 5. Libro de Composición de Arthur Wesley Dow. 2da edición publicada en 1899. Fuente:_https://www.worthpoint.com/worthopedia/1899-arthur-wesley-dow-composition-1927375693

La segunda razón se relacionaba a la importancia que Chang daba a la procedencia académica y su desconsideración hacia la metodología y los contenidos a la hora de delegar su asignatura. Chang procuró conseguir docentes occidentales o que tuvieran experiencia de estudio en Occidente. Entre ellos se encontraba el expresionista John L. Frank - el primer docente occidental a cargo de la asignatura en mayo de 1952—, Joseph Szekel —que se encargó en 1953 - y otros de quienes la SNU ha perdido registro.

Estos cambios de personal docente concluyeron en 1958, cuando Chang contrató a la artista coreana ChoungZa Kim. Kim había terminado su maestría en Painting Design en la Universidad Municipal de Oklahoma. Según ella, en 
el momento en que ingresó al Departamento de Artes Aplicadas todavía no existía una noción sobre qué era el diseño. Por ello, decidió dividir la clase de Composición en una parte teórica, en la que impartía los conceptos, y una práctica, en la que enseñaba la técnica del grabado (Park, 2013a, p. 39). En este aspecto, es importante analizar cuál fue la concepción enseñada por Kim, ya que era la primera vez que la materia Composición se trataba de definir y generar un marco teórico del Diseño.

Si bien los registros de las clases de Kim se perdieron del archivo de la SNU, el contenido se ha podido reconstruir a través de sus escritos y la memoria de sus estudiantes. Según relata SuEun Boo, ella se había esforzado por enseñar deliberadamente los contenidos que había aprendido en la Universidad de Oklahoma (Park, 2013b, p. 38). Min-Soo Kim (1996) hace mención de que Choung-Za Kim definía el diseño como "un hecho artístico basado en la técnica y utilidad" y que su enseñanza "estaba ligada a los elementos que la componían: línea, forma, color, textura, patrón, espacio; y a los principios de proporcionalidad, equilibrio, movimiento, repetición, énfasis y armonía" (p. 44).

Según estas descripciones, se pudo comprobar nuevamente que la importancia de la procedencia donde hacía hincapié Chang estaba en que los profesores debían cumplir el rol cuasi mecánico de contenedores informáticos. Por ello, no fue casual encontrar que tanto la definición de diseño como los conceptos utilizados por Kim eran los mismos que se encontraban en el libro Design: A creative approach ${ }^{3}$ de Emerson Sybil (Figura 6). Es decir, los docentes tenían la obligación de traducir la información manteniendo el sentido estricto del término aprendido, y transmitir sin hacer adaptación alguna a la realidad local. Debido a esto, y a pesar del esfuerzo de Kim, su clase hizo elevar varias voces

\footnotetext{
${ }^{3}$ Dicho libro se encontró en los materiales de archivos donados por la profesora Kim en el Instituto de Artes Visuales de la Universidad Nacional de Seúl. Dentro del libro se encontraron varias marcaciones y algunas notas en coreano y en inglés que se intuyen que fueron hechas por la profesora Choung Za Kim.
} 
entre alumnos que aún hoy recuerdan el contenido de la asignatura como desordenado (Park, 2013a, p. 34) y difícil de comprender (Kim, 2013b, p. 31).

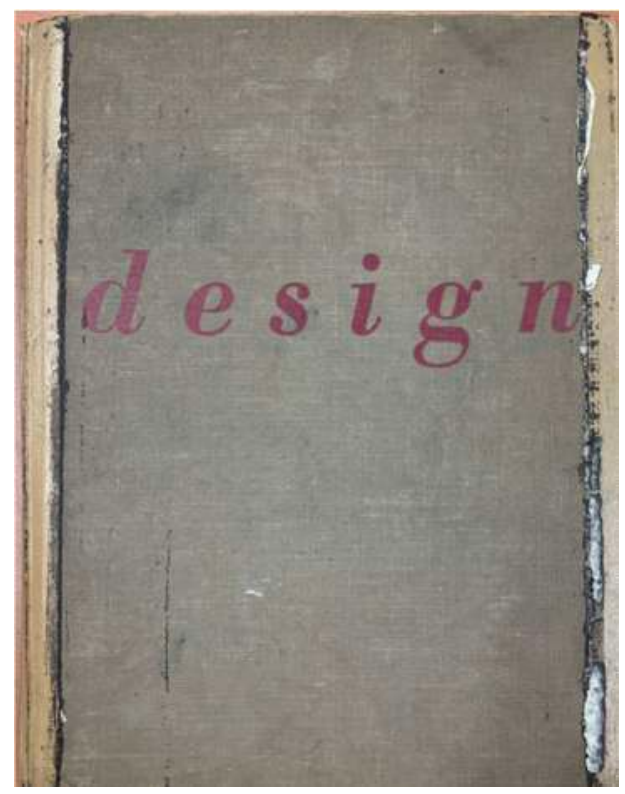

Figura 6. Design: A creative approach, de Sybil Emerson, 1953. Libro con el que la profesora Kim Choung Za impartía clases sobre teoría del diseño en la asignatura Composición.

Sin embargo, la disconformidad manifestada por los alumnos, que había llegado al punto de amedrentar a Kim, no solo señalaba el problema de dicha asignatura, sino que además demostraba el desorden general del Departamento de Artes Aplicadas. El desacuerdo docente general sobre qué era el diseño y la aplicación de la metodología extranjera sin ningún tipo de pensamiento crítico, habrían conducido a que la actividad del diseño en los años 50 fuese 
confusa en la SNU. De esta manera, la forma de aprender de los alumnos estuvo limitada a la especulación individual dentro de un taller compartido por todos los niveles. En la entrevista de YongMok Park (2013c) a Min Cheol Hong, puede apreciarse que:

El profesor Sun Seok Lee decía "producto artesanal", y creo que, en ese momento en la Escuela de Bellas Artes, sin usar la palabra "artesanía", se empezaba a hablar de "diseño de productos". (...) Como estábamos todos en el mismo taller, pude ver que las piezas de los alumnos de instancias superiores consistían en parasoles, carteras, es decir que no eran productos de industria pesada sino objetos cotidianos de industria ligera. (p. 70)

Más allá de las dudas de Hong, el ejemplo de su caso amerita un análisis, ya que simboliza un ciclo perfecto de formación, reformación e influencia académica. Hong fue uno de los alumnos que comenzaron sus estudios cuando todavía el Departamento se hacía llamar DoAn, y se graduaron cuando el nombre del Departamento cambió a Artes Aplicadas. El HDC le otorgó una beca en 1958 para cursar un año de Diseño Industrial en la Universidad Tecnológica de Illinois (Figura 7). Otro ejemplo similar al de Hong fue el de Sun Hyeon Kwon, quien realizó el mismo ciclo académico y recibió también la beca por el mismo centro norteamericano para que fuera a estudiar Diseño Gráfico al Instituto de Arte de Cleveland. Tanto Hong como Kwon culminaron sus estudios como becarios y se incorporaron en 1960 al plantel docente de la SNU. 


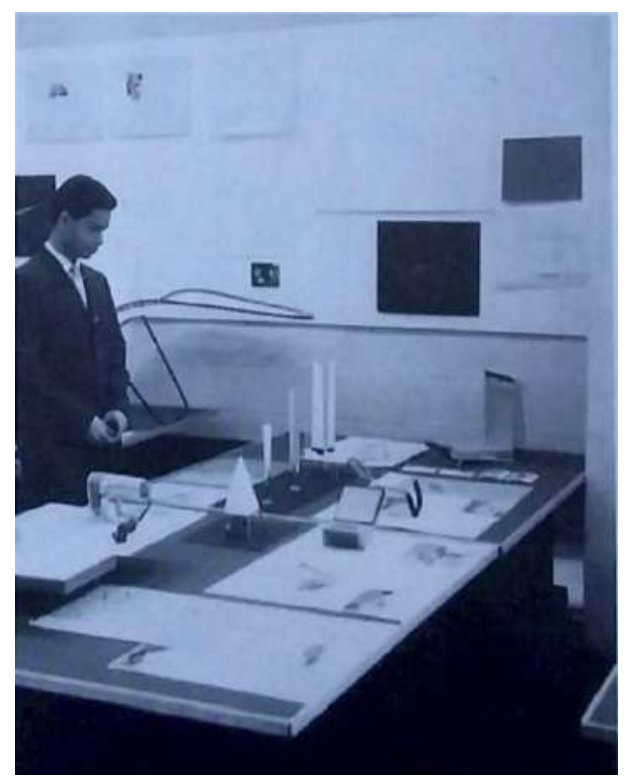

Figura 7. Min Cheol Hong en la exhibición de Diseño de la Universidad de Illinois a través de la beca del Handicraft Demonstration Center, 1959. Fuente: Instituto de Artes Visuales (1994, p. 19),

Luego de un año de su vuelta, Hong y Kwon realizaron una exposición de diseño en el que exhibieron sus respectivos portafolios. Los alumnos presentes en el evento habían quedado alucinados por la cantidad de croquis, prototipos y objetos nunca desarrollados en las clases de la SNU (Kim, 2013a, p. 32). Simplemente bastaba con observar los dos productos creados por Hong para comprender dicho revuelo académico. Una diferencia de tan solo un año alcanzaba para que el autor de la bandeja curvada de madera con motivos floreados (Figura 8) pasara a diseñar una radio moderna con superficies lisas y despojadas de motivos decorativos (Figura 9). De este modo, a simple vista parecía que la corta experiencia les había sido lo suficientemente impactante a ambos para 
revertir sus pensamientos y asimilar el nuevo estilo de "diseño americano". No obstante, lo que también estaba en evidencia era cuan interiorizado tenían lo de "la fórmula educativa" que se venía propagando en la SNU.

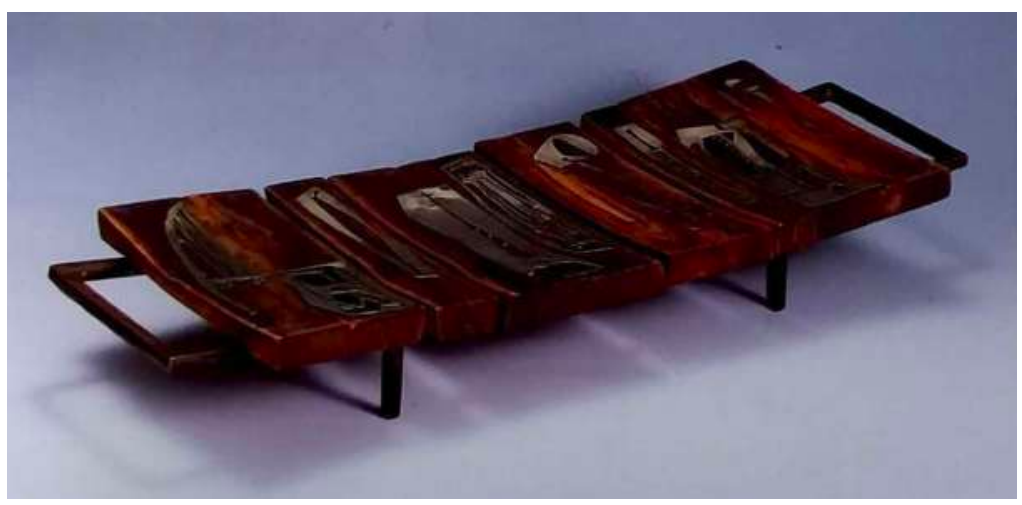

Figura 8. Diseño de bandeja de Min Cheol Hong antes de la Beca de Diseño, 1956. Fuente: Instituto de Artes Visuales (1994, p. 15)

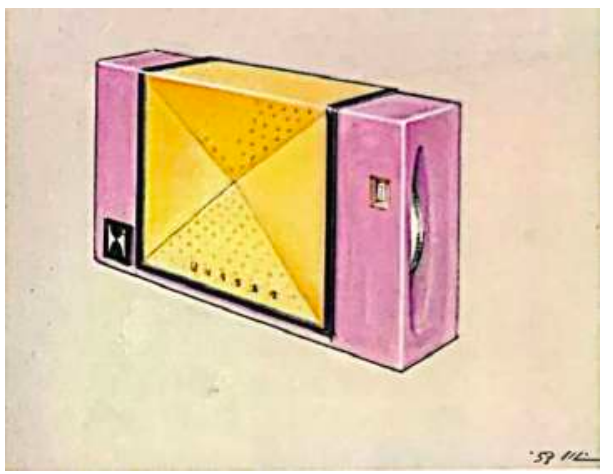

Figura 9. Prototipo de radio diseñado por Min Cheol Hong como trabajo práctico para la asignatura de Diseño de la Universidad de Diseño de Illinois, 1958 Fuente: Instituto de Artes Visuales (1994, p. 21). 
Por consiguiente, la incorporación de Hong y Kwon en el plantel docente fue el segundo punto de inflexión en la enseñanza del diseño. Tal como lo habían hecho sus exprofesores, Hong y Kwon - a cargo de la enseñanza del Diseño Industrial y Diseño Gráfico, respectivamente- conformaron la nueva hybris del punto cero (CastroGómez, 2005). Ambos se apresuraron a dejar en claro que la educación, hasta ese momento recibida en la SNU, no había sido sobre diseño. En una entrevista realizada en 2004, MinCheol Hong recuerda cómo había sido su educación en la SNU. Hong descalificaba los afiches gigantes que exponían en aquel momento los alumnos de grados superiores, aseverando que no eran diseño, ni diseño gráfico o arte (Korean Design Research Institute, 2004, p. 53). Evidentemente, la negación categórica estuvo íntimamente relacionada con la educación que recibió en la Universidad de Illinois, ya que su esfuerzo estaba en querer inculcar los conocimientos del diseño adquiridos en las respectivas universidades.

\section{Resultados académicos}

La reflexión mecánica de los nuevos ejercicios aprendidos en el extranjero se dio automáticamente desde el primer trabajo que lanzó Hong bajo el nombre de Industrial Design: el diseño de un teléfono fijo. La consigna del ejercicio constaba en que los alumnos diseñaran un objeto utilizable o no en la vida cotidiana, pero lo suficientemente innovador para despegarse de los modelos ya existentes. Sin embargo, los resultados no fueron sorprendentes: ninguno había podido superar la barrera de los componentes formales que constituían el teléfono.

Todos mantuvieron las mismas partes inamovibles del aparato: un auricular tubular apoyado sobre una gran carcasa, en la que predominaba un marcador rotatorio o botones de marcación y un cable que unía el auricular al cuerpo del aparato (Figura 10). Había ejemplos donde las variaciones morfológicas de color y el uso de formas geométricas proyectaban un objeto levemente fuera 
de lo convencional (Figura 11). De todas formas, el uso del Estilo Moderno ${ }^{4}$ de superficies limpias y despojadas de motivos decorativos era la mayor constante. Asimismo, la característica más paradójica fue que se habían presentado diseños modernos reproducibles, pero no realizables, ya que el ejercicio no había tenido en cuenta el mecanismo, la producción técnica o el circuito de componentes internos. Y al no conocer el carácter técnicoindustrial del producto, era imposible para el alumno salir del formato convencional del teléfono en cuestión.

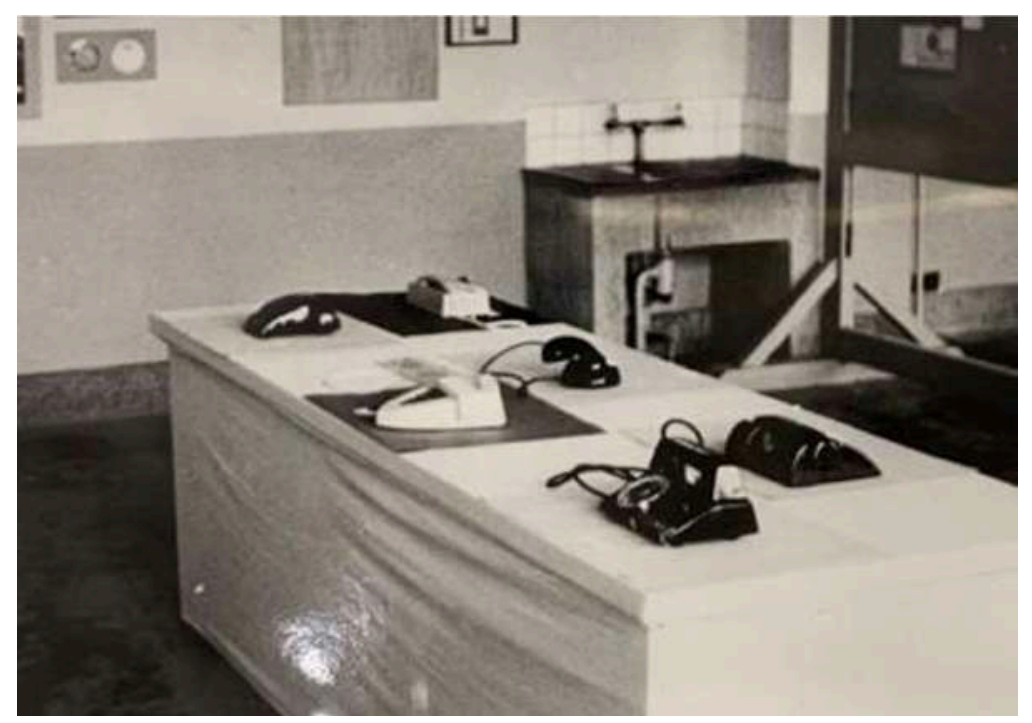

Figura 10. Resultados de alumnos del primer trabajo práctico de Diseño Industrial en la materia dirigida por Min Cheol Hong, 1963. Fuente: SNU, Visual Art Institute.

\footnotetext{
${ }^{4}$ Lo que aquí se describe como Estilo Moderno refiere al estilo funcionalista desarrollado en las principales escuelas de diseño del siglo XX. Consiste en mostrar una gran simplificación de formas acentuando la claridad y la función del diseño. Se intuye que Min Cheol Hong habría adquirido esta bajada morfológica durante su estadía en la Universidad Tecnológica de Illinois que no casualmente había tomado el legado de la Nueva Bauhaus fundada en Chicago por Moholy Nagy en 1937. Por lo tanto, se puede deducir que Hong tuvo la oportunidad de aprehender indirectamente la filosofía y la morfología de la Nueva Visión.
} 


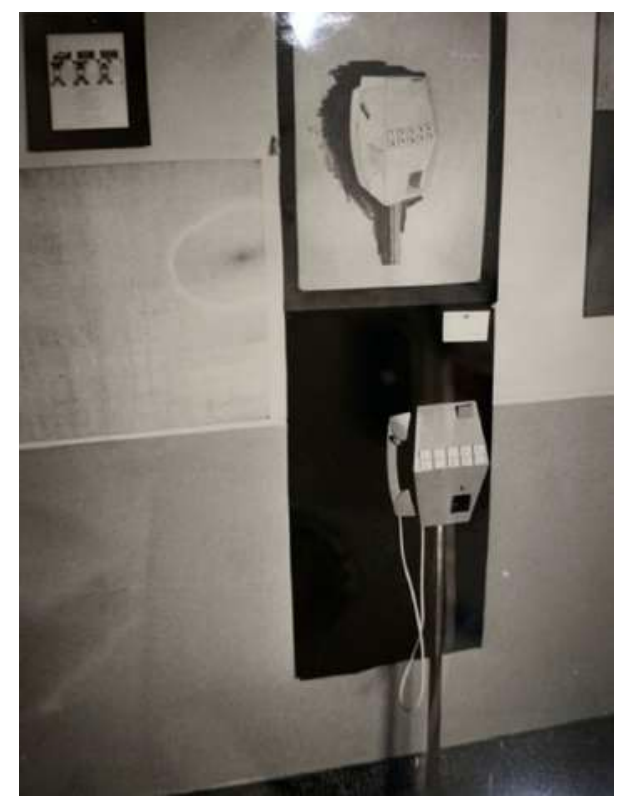

Figura 11. Prototipo de uno de los teléfonos diseñados por los alumnos en el trabajo práctico de 1963. Fuente: SNU, Visual Art Institute.

A través de los proyectos finales del alumnado, se puede observar que en el área gráfica —al igual que en el área de diseño de productos—, la obligación de incorporar diferentes estilos americanos de diseño era notable. Sin un eje lineal, los estilos variaban entre afiches más sobrios que hacían uso de la tipografía Sans Serif e imágenes pictóricas cuasi geométricas, mientras otros hacían uso de la técnica del collage, técnica con la que remarcaban la tipografía como imagen o agregaban ilustraciones lúdicas similares a las del diseñador Saul Bass de la Escuela de Nueva York (Figura 12). Todo era válido mientras se usara la matriz del Estilo Americano. Fue así como, con la 
importación de un nuevo Estilo Moderno, y haciendo más uso de la palabra Design, el paradigma del "dibujo de mesa" y de educar en el diseño como un aspecto externo decorativo del producto siguió vigente hasta fines de los 70.

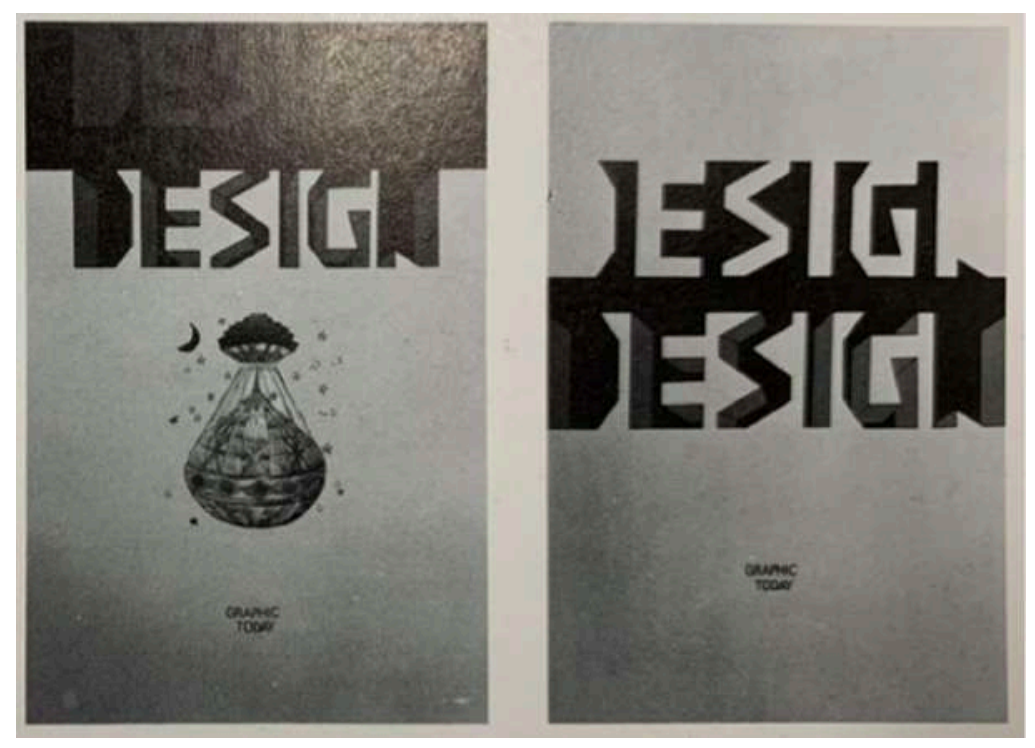

Figura 12. Proyecto de Graduación de 1972 de la alumna Kyung Mi Lee. Fuente: Álbum de graduación número 27 (1972). Seúl, Escuela de Bellas Artes, SNU.

Paralelamente, también estuvieron presentes los docentes que siguieron cuestionando la problemática de la identidad coreana durante los años 60 y 70. En especial, la cohorte de exalumnos — tales como Kyo Man Kim, Sung Chun Jang, Soo Un Boo, Young Jae Jo, entre otros-, ya convertidos en profesores, optaron por seguir la tradición de Sun Seok Lee. Ellos aceptaron gratamente el nuevo lenguaje lleno de variables visuales similares a la gráfica de la Escuela de Nueva York, pero vieron la necesidad de seguir trabajando 
con los elementos de la "coreanidad" que, fuera del acuerdo tácito académico, nunca había sido definida.

Según lo analizado de diferentes trabajos prácticos, una serie de elementos formales y de contenido eran lo que remitía al imaginario tradicional coreano. Fue así como la incorporación de animales simbólicos como el tigre y el oso, la vestimenta tradicional Han Bok, los abanicos coreanos, los lugares icónicos de Corea y los motivos florales eran algunos de los temas más recurrentes. Lo mismo pasaba con el uso de ciertos colores, la reminiscencia de elementos de la caligrafía coreana Seo Hye o la aplicación de ciertos aspectos estéticos de las cerámicas o muebles tradicionales de Joseon, cuando la bajada del trabajo práctico hacía referencia a la coreanidad. La misma era también un pedido recurrente para los proyectos nacionalistas del gobierno de Park. Por ejemplo, estuvo ligada a la propuesta que el mismo plantel docente le había hecho al Gobierno a principios de los años 60.

En esa década, la duda en el ámbito académico acerca de qué era diseño había dejado de importar tanto cuando la confusión se convirtió en cotidianeidad. La sobreutilización de la palabra Design daba lugar a un acuerdo tácito entre el staff docente, que asentía al oírla mencionar. Ellos ya no hablaban en términos de artes y dibujos, sino de algo superlativo que debían dar a conocer a la sociedad. Luego de que el HDC sugiriera a la sociedad que el diseño podía ser rentable, el grupo de docentes de la SNU —encabezado por Sun Seok Lee, Min Cheol Hong, Sun Hyeon Kwon y Young Jae Jo, más dos docentes de la Universidad Hongik y otros-, sintió la necesidad de promover la práctica del diseño.

El grupo decidió tener una reunión con el Ministerio de Comercio e Industria a mediados de los 60 para convencer al Gobierno de que el diseño podía promover los objetivos del primer plan quinquenal (19621966). El Ministerio 
de Comercio e Industria, inducido por la idea de que el diseño podría servir como una herramienta para mejorar la calidad estética de los productos exportables y así permitir la competencia en el mercado internacional, dio lugar a la formulación de dos decretos relacionados al diseño en la junta de políticas para la expansión de exportaciones en la casa de gobierno el 13 de septiembre de 1965. El primero consistió en la formación de la Exposición de Artes Industriales de la República de Corea (Korean Industrial Art Exhibition) el 1 de junio de 1966, dirigido por la Junta del Comercio e Industria, para dar a conocer las actividades del diseño en la sociedad. El segundo fue la reunión de un consejo de profesionales el 4 de junio para planear la fundación del Centro de investigación coreano de Artesanía y Diseño (Korean Handicraft Design Center - KHDC-).

Finalmente, el grupo de docentes había logrado su cometido: el establecimiento de dos instituciones que iban a difundir las actividades del diseñador y la significación del diseño en Corea. Además, era de esperarse que, tanto el jurado de la exhibición nacional como el grupo de investigación del centro, serían integrados por los mismos docentes que habían persuadido al presidente de que el diseño podía estar al servicio del progreso nacional.

Park no dudó en asistir y alentar dichos proyectos. Su participación en la inauguración de la Korean Industrial Art Exhibition (Figura 13), su continua asistencia económica y el mismo regalo que había confeccionado para el centro de investigación simbolizaban su apoyo. Pero su inversión era tan contundente como las palabras manifestadas en su cuadro caligráfico: Suchul Misul —“Arte de Exportación" - (Figura 14). Sus palabras dejaban en claro cuál era su entendimiento del diseño y qué pretendía obtener de él. A su vez, las noticias en todos los periódicos del país potenciaron el interés general del público que concurría a las exhibiciones. De esta manera, la exhibición daba a conocer el famoso fenómeno indefinido del diseño a través de sus productos. 


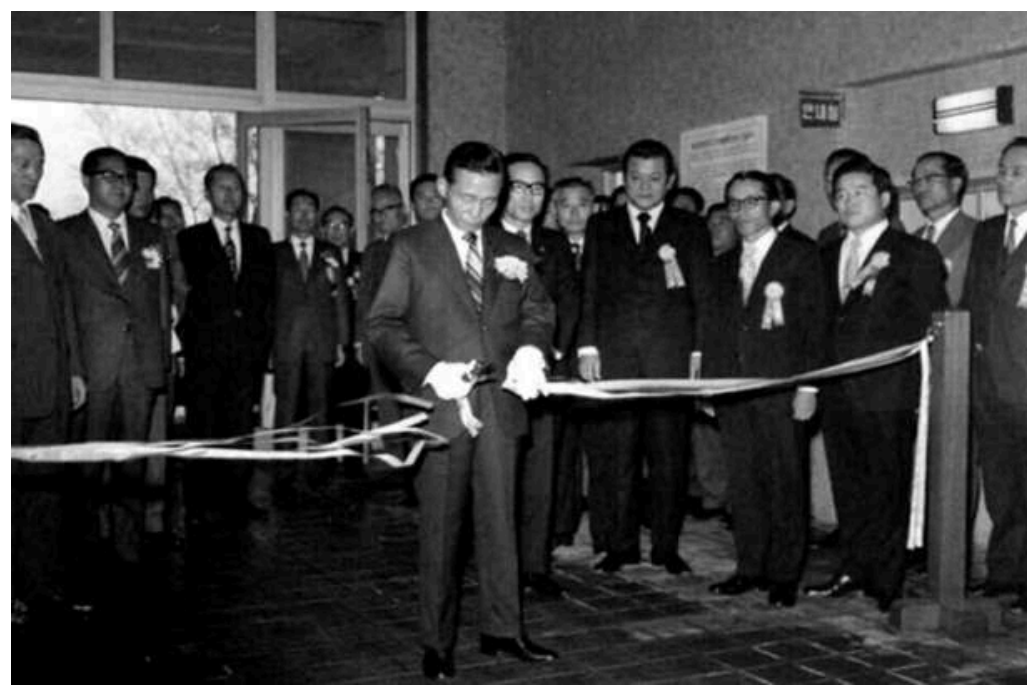

Figura 13. El presidente Park Jung Hee cortando el cinto en la ceremonia de inauguración del Centro de Exposiciones de Arte Industrial de 1966. Fuente: National Archive of Korea.

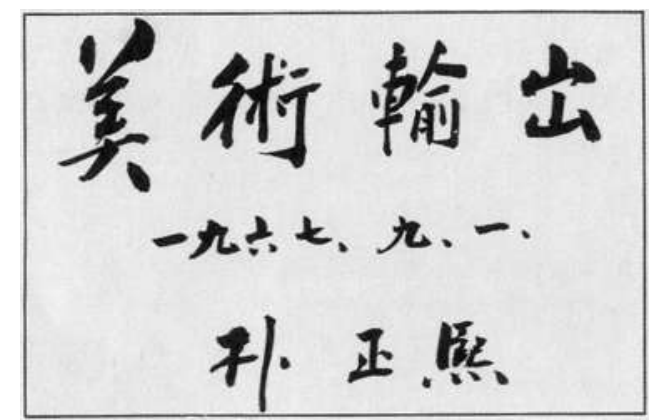

Figura 14. Regalo que el presidente Park Jung Hee hace al Korean Handicraft Design Center. La imagen aparece en la contraportada de la revista Design editada por el mismo centro.
Fuente: revista Diseño, trimestral, Número 1, 1969. 
En paralelo, el KHDC se posicionaba como una institución semiestatal dentro del campo universitario de la SNU (Figura 15). Lamentablemente, la gran diferencia de intereses entre el Gobierno y los investigadores del centro hizo que se disolviera en menos de dos años. No obstante, la brevedad de su estancia no justificaría su desvalorización. El predominio de docentes de la SNU le otorgó un carácter monopólico, ya que Sun Seok Lee, como director del centro, había establecido por contrato que los investigadores fueran los mismos docentes de la Escuela de Bellas Artes (Certificado de registro del Instituto de Investigación de Diseño de Artesanía de Corea, 1966). Y esta característica hizo que el centro tuviese un carácter más teórico que práctico, un verdadero laboratorio de ideas. Según resultados publicados en Gegan Design, revista trimestral emitida por el mismo centro, se puede observar que el centro había brindado un espacio para el pensamiento, la discusión y el ordenamiento de ideas sobre el diseño. Asimismo, no es un detalle menor que este evento haya sido esencial en la historia de la política de diseño y la educación: fundó las bases del primer centro de diseño coreano, antesala del centro de promoción formal de Corea de 1971, el Korean Design Packaging Center (KDPC).

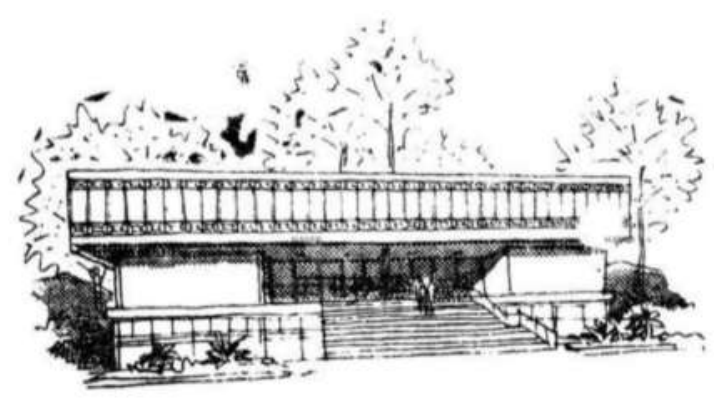

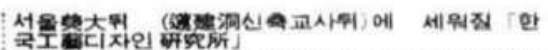

Figura 15. Ilustración del departamento de Korean Handicraft Design Center en el Campo Universitario de la Universidad Nacional de Seúl en 1966. Fuente: "El centro de Diseño y Artesanía que recibe los rayos del sol", 1966, 8.1, Diario Kyung Hyang. 
Desafortunadamente, un año de trabajo no era suficiente tiempo para reelaborar la manera de enseñar el diseño y para modificar todo el esquema universitario. Por ello, las pautas de los trabajos prácticos de diseño se limitaron a las exigencias del Estado; de esta manera, los alumnos podrían finalizar sus proyectos a presentar en la Exhibición de Arte Industrial. Los alumnos trabajaban sobre la promoción de Corea en el extranjero y hacían uso de todos los estilos estéticos aprendidos. Imágenes con altos contrastes, colores destellantes, estilo Pop Art (Figura 16), el collage, el uso de tipografía como imagen (Figura 17), todos los detalles estéticos eran bienvenidos mientras se evidenciara un dominio de la estética occidental y el contenido remitiese a Corea (Figura 18).

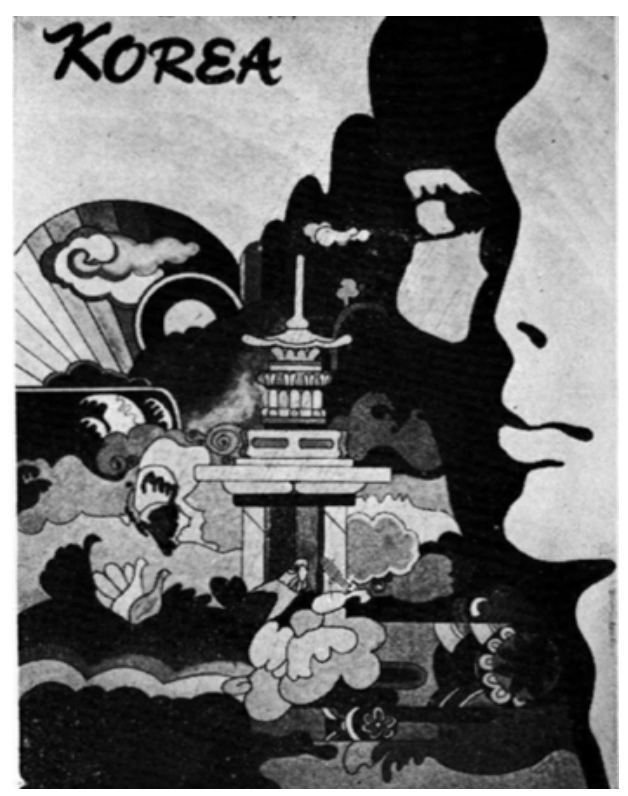

Figura 16. Proyecto de Graduación del Departamento de Artes Aplicadas de 1973. Poster turístico en estilo Pop Art. Fuente: Álbum de graduación número 28 (1973). Seúl, Escuela de Bellas Artes, SNU. 


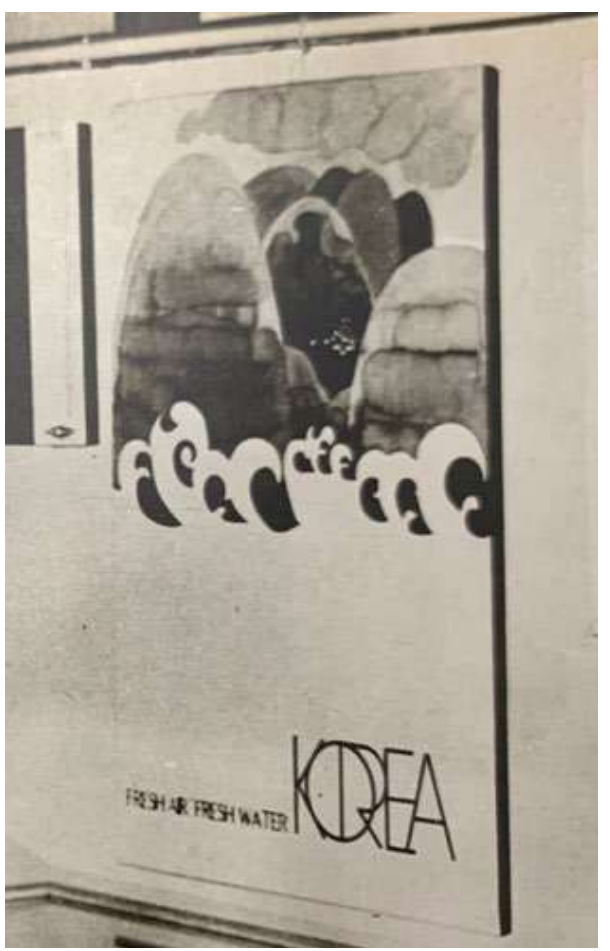

Figura 17. Proyecto de Graduación del Departamento de Artes Aplicadas de 1973. Diseño de posters de la alumna Pil Suk Park. Fuente: Álbum de graduación número 28 (1973). Seúl, Escuela de Bellas Artes, SNU. 


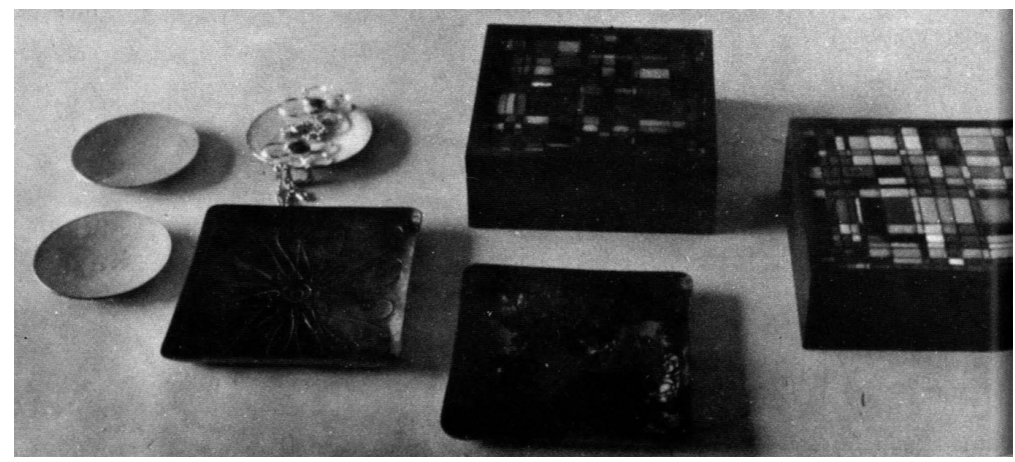

Figura 18. Cenicero, Caja, Cerámica, de la alumna Mi Sun Park. Proyecto de Graduación de 1971. Fuente: Álbum de graduación número 26 (1971). Seúl, Escuela de Bellas Artes, SNU.

De este modo, más por un interés políticocomercial que por la necesidad de reflexión existencial de identidad, la adaptación de motivos historicistas y antigüedades folclóricas coreanas, el estilo moderno siguió hasta fines de los años 80 de modo expansivo. Todos los resultados ya se habían popularizado a través de la participación de los mismos alumnos que, no casualmente, ganaban las exposiciones evaluadas por sus mismos docentes.

\section{Conclusiones}

La recopilación, el análisis y la interpretación de documentos históricos relacionados a la educación del diseño en la Universidad Nacional de Seúl (SNU) entre las décadas de 1940 y 1970 lograron poner en evidencia que el complejo proceso de formación del concepto de diseño en Corea del Sur estuvo ligado a la sucesiva importación y adopción de conceptos extranjeros. La historia del advenimiento del diseño puede ordenarse en las siguientes etapas: 
La primera, en la que se interpreta el diseño como una mera decoración superficial del producto, y donde la influencia de EE. UU. no solo no da tiempo a un replanteamiento del concepto de diseño, sino que además le adhiere un valor de producto comercial.

La segunda, en la cual este hecho es reflejado en la formación académica de la SNU a través de la lucha de dos grupos ideológicos que se preocuparon por generar una reflexión mecánica del contenido académico extranjero. El egocentrismo de los dos bandos, acompañado por cambios rápidos y constantes de profesores con diversas formaciones, entorpeció la búsqueda de una reelaboración y reflexión acerca del concepto del diseño. Asimismo, la aplicación indiscriminada de contenidos occidentales desencadenó una confusión general en los inicios de la carrera que, sin superar la pedagogía previa, se reflejó en la comprensión del diseño por parte del alumnado.

La tercera, en la que se manifiesta la manera en que se estructura la forma de pensar y producir el diseño en relación con las políticas desarrollistas de diseño del gobierno de Park. Desde los años 60 el plantel docente de la SNU queda ligado fundamentalmente a las necesidades del Gobierno, que comprendió la actividad del diseño como un mero aspecto decorativocomercial que podría servir para aumentar la venta de bienes exportables. Este hecho se reflejó en que el diseño se diera a conocer en la sociedad como una actividad decorativa rentable, destinada a la producción de objetos promocionales coreanos diseñados bajo una forma universal exportable. 


\section{Referencias}

Abela, J. A. (2002). Las técnicas de análisis de contenido: una revisión actualizada. Fundación Centro de Estudios Andaluces.

Barthes, R. (1972). Mythologies (A. Lavers, Trad.). Hill and Wang. (Obra original publicada en 1957).

Berman, M. (2011). Todo lo sólido se desvanece en el aire: la experiencia de la modernidad (A. Morales Vidal, Trad.). Siglo XIX. (Obra original publicada en 1982).

Campi, I. (2015). El diseño de producto en el siglo XX: Un experimento narrativo occidental (tesis de doctorado). Universitat de Barcelona, Barcelona.

CastroGómez, S. (2005). La hybris del punto cero: ciencia, raza e ilustración en la nueva granada (17501816). Pontificia Universidad Javeriana.

Cauzzi de Gosende, T. (1996). Educación en Corea del Sur: Instrumento del Desarrollo. Iberoamérica, (7), 5577.

Certificado de registro del Instituto de Investigación de Diseño de Artesanía de Corea, BA01234359. (1966). Ministerio de Comercio e Industria, Seúl.

Choi, Y. K. (2009). La belleza del dolor que se encuentra en el arte popular de Joseon por Yanagi Muneyoshi en: "Mirando a Dios a través de la belleza del dolor". Religion and Culture, (16), 79104.

Command, U. N. (1958). Stabilization and program progress: fiscal year 1958, Korea. Office of the Economic Coordinator for Korea.

Dow, A. W. (1913). Composition; a series of exercises in art structure for the use of students and teachers (7ma ed.). Garden City.

Dow, A. W. (1920). Composition: Understanding line, notan and color (9th ed.). Double day, Page\&Co.

Forty, A. (1986). Objects of Desire: Design and Society since 1750. Pantheon.

Giedion, S. (1948). Mechanization Takes Command. University of Minnesota.

Her, B.H. (2009). Kwon Sun Hyeong y la cerámica contemporánea coreana. Mijinsa. 
Instituto de Artes Visuales. (1994). El nuevo horizonte del Diseño: Min Cheol Hong. Min Cheol Hong y 40 años de Diseño Industrial. Mijinsa.

Instituto de Artes Visuales. (1996). Modern art education in Korea and the College of Fine Arts, Seoul National University, 1946 1960. Celebración de los 50 años de la Universidad Nacional de Seúl. Universidad Nacional de Seúl.

Instituto de Artes Visuales. (2016). 70 años de la Escuela de Bellas Artes de la Universidad Nacional de Seúl. Instituto de Artes Visuales, SNU.

Jeong, Y.-M. (2010). Crítica biográfica de Jang Pal. Archivo del Instituto de Artes Visuales SNU (2), 7-37

Kim, E. (2020). The Design Coloniality of South Korea and Argentina: The history and development of Governmental Design Promotion and Education during the 195070s (Tesis de doctorado). Seoul National University, Seoul.

Kim, M.S. (1996). 50 años de la educación de Diseño y Artesanía en la Escuela de Bellas Artes de la Universidad Nacional de Seúl (pp. 3157). Escuela de Bellas Artes, Simposio del Instituto de Artes Visuales.

Kim, S.Z. (2013a). El amanecer del diseño coreano. Archivo de la Escuela de Bellas Artes de la Universidad Nacional de Seúl: El Diseño de Yang Sung Chun. Instituto de Artes Visuales, SNU.

Kim, S.Z. (2013b). El amanecer del diseño coreano. Archivo de la Escuela de Bellas Artes de la Universidad Nacional de Seúl: El Diseño de Jo Young Jae. Instituto de Artes Visuales, SNU.

Korea Design Packaging Center. (1990). 20 años de Korea Design Packaging Center. Korea Design Packaging Center.

Korean Design Research Institute. (2004). Diálogo con la memoria: El diseño moderno y Boo Su Hyun. KDRI.

Lee, J.-R. (2017). Estudio en torno al estado de los estudiantes coreanos en Beijing antes y después de la década de 1920. Gaseta China, (80), 231-262.

Mignolo, W. (2011). The darker side of Western modernity: global futures, decolonial options. Duke University Press.

Mumford, L. (1934). Technics and Civilization. Harcourt. 
Noguero, F. L. (2002). El análisis de contenido como método de investigación. Revista de Educación, 4, 167-179.

Park, Y.M. (2013a). El amanecer del diseño coreano. Archivo de la Escuela de Bellas Artes de la Universidad Nacional de Seúl: El Diseño de Kim Chung Za. Instituto de Artes Visuales, SNU.

Park, Y.M. (2013b). El amanecer del diseño coreano. Archivo de la Escuela de Bellas Artes de la Universidad Nacional de Seúl: El Diseño de Boo Su Hyun. Instituto de Artes Visuales, SNU.

Park, Y.M. (2013c). El amanecer del diseño coreano. Archivo de la Escuela de Bellas Artes de la Universidad Nacional de Seúl: El Diseño de Min Cheol Hong. Instituto de Artes Visuales, SNU.

Pevsner, N. (1949). Pioneers of Modern Movement. Museum of Modern Art.

Pulos, A. (1989). The American Design Adventure. The MIT Press.

Schaefer, H. (1970). The Roots of Modern Design: Functional Tradition in the 19th Century. Studio Vista.

Universidad Nacional de Seúl. (1993). La Escuela de Bellas de la Universidad Nacional de Seúl: 19461993. Escuela de Bellas Artes, SNU.

Cómo citar: Kim, E. (2022). Reflexiones y refracciones modernas: el advenimiento de la enseñanza del Diseño en la Universidad Nacional de Seúl entre las décadas de 1940 y 1970. Revista KEPES, 19(25), 325-361. https://doi.org/10.17151/kepes.2022.19.25.12 